\title{
A COMPARISON BETWEEN UNDERGRADUATE POLYTECHNIC AND MEDICAL EDUCATION SYSTEMS IN ROMANIA
}

\author{
Liana Dehelean, ${ }^{1}$ Ana Maria Romosan, ${ }^{2}$ Petru Papazian, ${ }^{3}$ Mircea Babaita ${ }^{4}$
}

\begin{abstract}
Background: While medical and polytechnic education systems seem dissimilar in approach, they both share a certain level of difficulty. After graduating, polytechnic students find easy employment in national or multinational companies, whereas medical students are presented with more job opportunities abroad. The purpose of the study was to compare students' satisfaction with training and career preferences from a technical and a medical perspective. The methods were as follows: the study participants were divided in two samples (polytechnic and medical undergraduates) and asked to fill in a satisfaction questionnaire regarding their professional training. In addition, they were invited to express options about the intended future career. Results: we found no differences between the two samples regarding the participants' satisfaction with teaching staff and labs. Polytechnic students have more Ph.D. opportunities while medical students were more involved with participation in conferences. Satisfaction with lectures and practical projects was significantly higher among medical students. Conclusions: Both polytechnic and medical students rate their training as satisfying, and half of them consider leaving the country.
\end{abstract}

UDC Classification: 377; DOI: http://dx.doi.org/10.12955/cbup.v5.1019

Keywords: undergraduate education; medical; polytechnic; working opportunities; emigration;

\section{Introduction}

The Romanian higher education system relies basically on lectures, optional lectures, and practical work (laboratory, practical projects, and practice in a professional setting). Electronic learning is available through e-lectures and educational software. Transfers between different university centers are possible. Research teams are encouraged to include students.

As nowadays, performance indicators in higher education rely predominantly on research outcomes, education comes into second place. Concomitantly, a growing pressure is exerted on the higher education system from the environment (Van Vught, \& Westerheijden, 1994) represented by companies, governments, and students (Ramsden, 1998).

Assessing the quality of undergraduate education implies analyzing both objective and subjective data. The objective outcomes are represented by students' achievements at local, national, or international assessments (Kellaghan \& Greaney, 2001). When evaluating students, one has to keep in mind a complex of factors connected to "what" and "how" to assess (Epstein, 2007). Literature data show that the way the students perceive how they are evaluated influences their learning strategy (Struyven, et al., 2005). According to Lizzio, students' perceptions of their teaching environment are stronger predictors of learning outcomes at university than prior achievement at school (Lizzio et al., 2002). Resistance to shift from passive to active learning depends on class size, student population and dominant attitudes (Seymour, 2001). In this respect, subjective factors such as students' perceptions about their professional training may help improve the teaching-learning process.

Medical and polytechnic education systems share a certain level of difficulty imposing high standards for graduating. Although they appear to be different in the content of curricula, both focus on theoretical and practical knowledge. Medical education involves a more humanistic approach. Empathy defined as the ability to sympathize with, and provide support to another person, has been shown to be correlated with students' clinical competencies (Hojat et al., 2002). Moreover, in medical students, knowledge and skills must be supported by the comprehension of what others expect from physicians and how they will react to their words and actions (Becker et al., 2009). The aim of the present study is to compare students' satisfaction with training and career preferences from a technical and a medical perspective.

\footnotetext{
${ }^{1}$ Conf.dr. Dehelean Liana, University of Medicine \& Pharmacy Timisoara, Romania, Neurosciences-Psychiatry Department, lianadeh@umft.ro

${ }^{2} \mathrm{PhD}$ candidate Romosan Ana Maria, University of Medicine \& Pharmacy Timisoara, Romania, Neurosciences-Psychiatry Department, ana.romosan@gmail.com

${ }^{3}$ Sl.dr.ing. Papazian Petru, Politehnica University of Timisoara, Faculty of Electronics \& Telecommunications, Applied Electronics Department, petru.papazian@upt.ro

${ }^{4}$ Conf.dr.ing. Babaita Mircea, Politehnica University of Timisoara, Faculty of Electronics \& Telecommunications, Applied Electronics Department, mircea.babaita@upt.ro
} 


\section{Method}

The study participants were medical and polytechnic students at Timisoara University of Medicine and Pharmacy and at Timisoara Polytechnic University respectively. The study was conducted by the Neuroscience/Psychiatric Department of Timisoara University of Medicine and Pharmacy in partnership with the Electronics and Telecommunication Engineering Department of the Polytechnic University of Timisoara. The students were invited to fill in a satisfaction questionnaire referring to their professional training. In addition, they were asked to express intentions about future career. The subjects were informed about the purpose of the study and the confidentiality of collected data. The questionnaire contains basic socio-demographic information (gender, age, year and type of training), closed-ended questions (yes/no opportunity type, or 1 to 5 satisfaction type). The yes/no questions referred to the opportunity to participate at optional lectures, national and international conferences, case presentations (for medical students) or practical projects (for polytechnic students), doctoral (Ph.D.) programs, or transfer between different university centers. The questions rated from 1 (poor satisfaction), to 5 (highest satisfaction) concerned the students' satisfaction with lectures, teaching staff (professors), and practical activity (in hospitals or laboratories, accordingly). The sources of professional information were also asked (provided by professor, self-research or both). Regarding their financial situation, students were asked to choose what best reflects their subjective perception (good, average, and very good). Additional questions referred to the intended career (academic or not), country of practice (home or abroad), and work setting (hospital, ambulatory or both in medical students, multinational corporation or small private business in polytechnic students). Personal options, comments or explanations were permitted through open ended questions.

\section{Results}

The study included 75 medical and 73 polytechnic students. In the medical students' sample, women were predominant $(78.6 \%)$. By contrast, in the polytechnic students' sample, $61.6 \%$ of the students were men. The mean age was 24.3 years $(\mathrm{SD}=1.47)$ in the medical students' sample, and 20.9 years $(\mathrm{SD}=1.64)$ in the polytechnic students' sample.

Medical students were significantly more satisfied with the quality of the lectures than polytechnic students $(\mathrm{U}=2238, \mathrm{Z}=-2.01, \mathrm{p}=0.04)$. No significant differences were found concerning satisfaction with the teaching staff/professors, $(\mathrm{U}=2405, \mathrm{Z}=-1.35, \mathrm{p}=0.17)$, the majority of the students declaring their satisfaction and partial satisfaction. There were no significant differences between students in respect with their practical activity in hospitals or laboratories $(U=2362, Z=-1.49, p=$ 0.13 ) as observed in Table 1.

Table 2 shows the students' satisfaction with: optional lectures (ol); conference attendance (c); case presentations (cp) for medical students or practical projects (pp) for polytechnic students; transfer (t) between different university centers; and inclusion in Ph.D. programs (Ph.D.).

Participation to optional lectures $(U=1554, Z=-5.24, p=0.0001)$, case presentations $(U=1382.5$, $\mathrm{Z}=-6.48, \mathrm{p}=0.0001)$, and conferences $(\mathrm{U}=2313, \mathrm{Z}=-2.11, \mathrm{p}=0.03)$ is significantly higher in medical students. This result may be explained by the increased need of medical students to meet the demands of a challenging profession based on efficacy and accountability. According to BillingsGagliardi \& Mazor medical students' decision to attend non-required lectures depends on several factors such as previous experiences with the lecturer, predictions, learning preferences, learning needs at that particular time, but is mostly influenced by the need of maximizing learning (Billings-Gagliardi \& Mazor, 2007). A study conducted by Patel and collaborators reports that students from medical schools with a higher-intensity training curriculum reported higher satisfaction than students from medical school with a lower-intensity curriculum (Patel et al., 2009).

None of the medical students expressed an option to enroll in Ph.D. programs, while $35.6 \%$ of the polytechnic students wish to undergo doctoral studies. This may be a consequence of the fact that the polytechnic education system offers more time to spend in research activities.

We found significant differences between the two samples regarding transfers between different university centers. Polytechnic students were significantly more interested in expanding their knowledge within other higher education centers $(U=1870, Z=-4.61, p=0.0001)$. 


\begin{tabular}{|c|c|c|c|c|}
\hline \multirow{2}{*}{$\begin{array}{c}\text { Satisfaction with the lectures (l) / } \\
\text { professor (p) / hospital activity/ } \\
\text { laboratory (h/l) }\end{array}$} & \multicolumn{2}{|c|}{ Medical Students } & \multicolumn{2}{|c|}{ Polytechnic students } \\
\hline & No & $\%$ & No & $\%$ \\
\hline Level 1 (I) & 1 & 1.3 & 4 & 5.5 \\
\hline Level 2 (I) & 8 & 10.7 & 12 & 16.4 \\
\hline Level 3 (I) & 28 & 37.3 & 29 & 39.7 \\
\hline Level 4 (I) & 27 & 36.0 & 23 & 31.5 \\
\hline Level 5 (I) & 11 & 14.7 & 5 & 6.9 \\
\hline Level 1 (p) & 1 & 1.3 & 3 & 4.1 \\
\hline Level 2 (p) & 4 & 5.3 & 6 & 8.2 \\
\hline Level 3 (p) & 27 & 36.0 & 28 & 38.4 \\
\hline Level 4 (p) & 29 & 38.7 & 27 & 37.0 \\
\hline Level 5 (p) & 14 & 18.7 & 9 & 12.3 \\
\hline Level $1(\mathrm{~h} / \mathrm{l})$ & 2 & 2.7 & 2 & 2.7 \\
\hline Level 2 (h/l) & 9 & 12.0 & 12 & 16.4 \\
\hline Level 3 (h/l) & 25 & 33.3 & 27 & 37.0 \\
\hline Level $4(\mathrm{~h} / \mathrm{l})$ & 20 & 26.7 & 23 & 31.5 \\
\hline Level $5(\mathrm{~h} / \mathrm{l})$ & 19 & 25.3 & 9 & 12.3 \\
\hline
\end{tabular}

Table 2: Sample distribution according to satisfaction with optional lectures, conferences, case presentations/practical projects, rotations, and $\mathrm{PhD}$

\begin{tabular}{|c|c|c|c|c|}
\hline \multirow{2}{*}{$\begin{array}{c}\text { Satisfied with optional lectures (ol) / } \\
\text { conferences (c) / case presentations } \\
\text { (cp) or practical projects (pp) / } \\
\text { transfers (t) / PhD program (PhD) }\end{array}$} & \multicolumn{2}{|c|}{ Medical Students } & \multicolumn{2}{c|}{ Polytechnic students } \\
\hline Yes (ol) & 54 & $\%$ & No & $\%$ \\
\hline No (ol) & 21 & 72.0 & 21 & 28.8 \\
\hline Yes (c) & 26 & 34.7 & 52 & 71.2 \\
\hline No (c) & 49 & 65.3 & 59 & 14.2 \\
\hline Yes (cp/pp) & 70 & 93.3 & 32 & 43.8 \\
\hline No (cp/pp) & 5 & 6.7 & 41 & 56.2 \\
\hline Yes (t) & 5 & 6.7 & 28 & 38.4 \\
\hline No (t) & 70 & 93.3 & 45 & 61.6 \\
\hline Yes (PhD) & 0 & 0.00 & 26 & 35.6 \\
\hline No (PhD) & 75 & 100.0 & 47 & 64.4 \\
\hline
\end{tabular}

Source: Dehelean Liana, Romosan Ana Maria, Papazian Petru, Babaita Mircea

Table 3: Sample distribution according to the source of information

\begin{tabular}{|c|c|c|c|c|}
\hline \multirow{2}{*}{ Source of professional information } & \multicolumn{2}{|c|}{ Medical Students } & \multicolumn{2}{c|}{ Polytechnic students } \\
\cline { 2 - 5 } & No & $\%$ & No & \% \\
\hline Teaching staff & 54 & 72.0 & 53 & 72.6 \\
\hline Teaching staff and self-research & 18 & 24.0 & 18 & 24.7 \\
\hline Self-research (internet, books) & 3 & 4.4 & 2 & 2.7 \\
\hline
\end{tabular}

Source: Dehelean Liana, Romosan Ana Maria, Papazian Petru, Babaita Mircea

There were no significant differences between medical and polytechnic students $(\mathrm{U}=2712 ; \mathrm{Z}=-0.12$; $\mathrm{p}=0.9$ ) concerning their source of professional information (Table 3). In both samples information is provided mainly by the teaching staff. This finding may reflect an education system relying mostly on conventional lecture-based curricula and using a teacher centered model. On the other hand, selfresearch through textbooks, internet, or podcasts, has its own downsides, mainly the impossibility for the student to ask questions and of the teacher to receive verbal and non-verbal feedback. This may result in less engagement and lower motivation for study (Schreiber, Fukuta, \& Gordon, 2010). In addition to this, the values and experience of the teaching staff may influence students acting as models or reflective practitioners (Harden \& Crosby, 2000). 
Regarding the postgraduate career, the students had to choose between a medical and / or an academic based one. Students could express preferences for hospital work and ambulatory work alone, or a combination of both. Medical students favored hospital practice alone (37.2\%) or a combination of hospital and ambulatory practice $(36.0 \%)$. In what concerns the polytechnic students, the majority of them favor working in a multinational corporation (76.7\%), $13.7 \%$ favor small private companies and $5.5 \%$ were indifferent. Choosing a hospital or mixed hospital and ambulatory based practice may reflect a proactive attitude towards work, or some financial concerns. In polytechnic students, the choice of working in a multinational corporation reflects more clearly the financial incentives.

Only $8 \%$ of the medical students envisage a strictly university career, while $12 \%$ wish to have a combined medical (hospital and ambulatory) and university career. Among the polytechnic students, $4.1 \%$ wish to follow a strict university career. An academic career may be favored for its prestige. While the medical students included in the study are more interested in the academic career, they expressed no desire to enroll in a Ph.D. program. A possible explanation may be the fact that medical students are confronted after graduating with another 4 years of residency to be allowed to practice, and this may gain priority over doctoral studies.

In respect to the financial situation, there were no statistically significant differences $(U=2689, Z=-$ $0.333, p=0.73$ ) between medical and polytechnic students (Table 4). The majority of the subjects, regardless of their specialty, rate their financial status as "average."

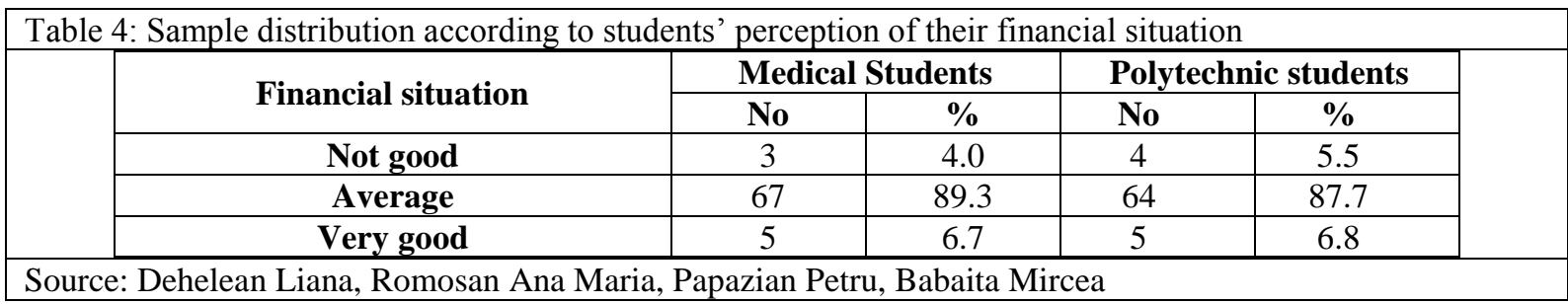

We found no statistically significant differences regarding emigration plans between the students from the two samples, while a greater number of medical students intend to practice abroad (Table 5). After graduating, polytechnic students find easy employment in national or multinational companies, whereas medical students are presented with more job opportunities abroad.

\begin{tabular}{|l|l|c|c|c|c|}
\hline \multicolumn{6}{|c|}{ Table 5: Sample distribution according to the intended place of future practice } \\
\hline \multirow{3}{*}{ Place of future medical practice } & \multicolumn{2}{|c|}{ Medical Students } & \multicolumn{2}{c|}{ Polytechnic students } \\
\cline { 3 - 6 } & No & \% & No & \% \\
\cline { 2 - 5 } & Outside Romania & 40 & 53.3 & 29 & 39.7 \\
\cline { 2 - 5 } & In Romania & 35 & 46.7 & 44 & 60.3 \\
\hline Source: Dehelean Liana, Romosan Ana Maria, Papazian Petru, Babaita Mircea \\
\hline
\end{tabular}

\section{Conclusions and limitations}

Medical students are significantly more satisfied with lectures, either optional or non-optional and practical project. While the medical training system encourages students to attend conferences, the polytechnic one offers more Ph.D. opportunities and student exchanges between universities. Both polytechnic and medical students rate their training as satisfying. However, more efforts should be envisaged from the teaching staff to encourage self-learning.

Half of medical and polytechnic students consider leaving the country as an option, with no significant differences between the two samples regarding the intention to work abroad.

The present study was conducted in Timisoara University Center, and does not intend to generalize the results for all the country.

\section{References}

Becker H. S., Geer B., Hughes E. C. and Strauss A. L. (2009). Boys in white. Student culture in medical school. New Brunswick: Transaction Publishers, (Chapter 1).

Billings-Gagliardi S. and Mazor, K. M. (2007). Student Decisions about Lecture Attendance: Do Electronic Course Materials Matter? Academic Medicine, 10, 73-76.

Epstein, R. M. (2007). Assessment in Medical Education. The New England Journal of Medicine, 356, 387-396. 
Harden R. M. and Crosby J. (2000). AMEE Guide No 20: The good teacher is more than a lecturer - the twelve roles of the teacher. Medical Teacher, 22, 334-347.

Hojat M., Gonnella J. S., Mangione S., Nasca T. J., Veloski J. J., Erdmann J. B., Callahan, C. A. And Magee, M. (2002). Empathy in medical students as related to academic performance, clinical competence and gender. Medical Education, 36, $522-527$

Kellaghan T., \& Greaney V. (2001). Using assessment to improve the quality of education. Paris: UNESCO International Institute for Educational Planning.

Lizzio, A., Wilson K. and Simons R. (2002). University Students' Perceptions of the Learning Environment and Academic Outcomes: Implications for theory and practice. Studies in Higher Education, 27, 17-52.

Patel M. S., Lypson M. L. and Davis M. M. (2009). Medical Student Perceptions of Education in Health Care Systems. Academic Medicine, 9, 1301-1306.

Ramsden P. (1998). Learning to lead in higher education. New York: Routledge, (Chapter 1).

Seymour E. (2001). Tracking the Processes of Change in US Undergraduate Education in Science, Mathematics, Engineering, and Technology. Sci Ed, 86, 79-105.

Schreiber B. E., Fukuta J. and Gordon, F. (2010). Live lecture versus video podcast in undergraduate medical education: A randomised controlled trial. BMC Medical Education, 10, 1-6.

Struyven K., Dochy F. and Janssens, S. (2005). Students' perceptions about evaluation and assessment in higher education: a review. Assessment \& Evaluation in Higher Education, 30, 331-347.

Van Vught F. A. and Westerheijden, D. F. (1994). Towards a general model of quality assessment in higher education. Higher Education, 28, 355-371. 